\title{
Avaliação do Tempo de Contato na Remoção de ĺons Cd(II) em Águas Utilizando Casca de Coco Seco (Cocos Nucifera L.) como Adsorvente
}

\author{
Danúbia O. Melo, Lorenna A. Antunes, Túlio N. Matos, \\ Cleide S. T. Araújo \& Hélen C. Rezende
}

A produção exorbitante de resíduos poluidores, originados de atividades industriais tem causado grande impacto ambiental. Entre esses contaminantes estão os íons metálicos, como $\mathrm{Cd}(\mathrm{II})$, que desperta grande preocupação, especialmente quando a contaminação afeta ambientes aquáticos. Em vista desse cenário crítico em relação aos recursos hídricos do planeta, é necessário procurar meios alternativos para tratar esses efluentes. A adsorção utilizando casca de coco seco como material adsorvente tem se mostrado boa alternativa, pois demanda de baixo custo.

Palavras Chave: Adsorção; Metais Tóxicos; Adsorvente Natural; Coco.

The exorbitant production of polluting waste from industrial activities has had a great environmental impact. Among these contaminants are the metal ions, such as Cd (II), which arouses great concern, especially when contamination affects aquatic environments. In view of this critical scenario regarding the planet's water resources, it is necessary to search for alternative means to treat these effluents. The adsorption method was applied using dry coconut shell as adsorbent material, since it is a low cost technique. For the analyzes the univariate method will be applied, where the analyzed variable will be time.

Keywords: Adsorption, Toxic Metals; Natural Adsorbent; Coconut. 


\section{Introdução}

Água é um recurso natural fundamental para a existência e conservação da vida (CHANDRA, 2010). No Brasil há uma vasta quantidade de recursos hídricos, no entanto o consumo exorbitante de água e a contaminação proveniente de atividade industriais e urbanas vem ocasionado a degradação dos mesmos (SILVA, 2016). Tendo em vista tal importância e considerando cenário atual da qualidade dos recursos hídricos, muitos estudos vêm sendo aplicado afim de melhor e preservar os ambientes aquáticos (RIBEIRO et al., 2012).

Com o crescimento das atividades industriais aumentouse a produção de resíduos contaminantes e o despejo inadequado desses vem acarretando sérios danos ao ecosistema, especialmente aos ambientes aquáticos (ASSIS, 2012). Os efluentes industriais são formados pelas mais diversas substâncias orgânicas e inorgânicas não aproveitadas nos processos industriais (MAXIMIANO, 2008).

Neste contexto o tratamento adequado dos efluentes tornou-se um dos pontos mais importantes associados às práticas industriais, especialmente quando o efluente contém metais tóxicos (TAVARES, 2013), pois esses apresentam alto potencial de toxicidade a todos os seres vivos e ao meio ambiente, e quando ingeridos, mesmo em pequenas quantidades, mas por um longo período, pode acumular-se no organismo causando sérios danos à saúde (RODRIGUES, et al, 2016).

Os metais tóxicos podem se dividir em dois grupos os oligoelementos, que são necessários para o organismo, como $\mathrm{Zn}, \mathrm{Cr}$, Co, e os sem função biológica como $\mathrm{Cd}, \mathrm{Pb}$, $\mathrm{Ni}$, que podem se acumular no organismo gerando graves doenças (LIMA \& MERÇON, 2010).

$\mathrm{O}$ cádmio faz parte do grupo que não desempenha nenhuma função biológica e o seu acúmulo no organismo pode levar a problemas renais, enfraquecimento dos ossos, doenças hepáticas e alteração no sistema nervoso (ATDSR, 2012). Além disso o Departamento de Saúde e Serviços Humanos dos EUA (DHHS) determinou que o cádmio e seus compostos são considerados cancerígenos (ATDSR, 2012).

Para a remoção desses íons contaminantes em meios aquosos, tem sido aplicadas várias técnicas convencionais como, precipitação química e troca iônica, entretanto necessitam de custos elevados, tanto para a implantação como para operação (AFONSO et al., 2011).A busca por novas técnicas de remoção de íons metálicos em sistemas aquosos tem crescido significativamente, como alternativa viável, tanto economicamente como ecologicamente, surgiu o uso de biomassas, especialmente subprodutos agroindustriais como material adsorvente (SILVA, 2013).

Entre eles estão os lignocelulósicos, como casca de coco, arroz, e amendoim, sabugo de milho, dentre outros, que tem despertado o interesse na área de pesquisas por serem de fácil obtenção e alta disponibilidade. Sua composição é basicamente celulose, hemicelulósicas e lignina, apresentam também proteínas e polissacarídeos, que possuem grupos funcionais como, ácidos carboxílicos, álcoois, fenóis e aminas (NETO et al, 2013). O presente trabalho propõe avaliar a influência do tempo no estudo da adsorção dos íons $\mathrm{Cd}(\mathrm{II})$ em agua utilizando as fibras da casca do coco seco (Cocos nucifera L.) "in natura", como material adsorvente.

\section{Metodologia}

As fibras do Cocos nuciferaL. "in natura" e sem nenhum tratamento químico foram obtidas na cidade de Uruaçu-GO no mês de setembro de 2017. As fibras foram separadas, lavadas com água deionizada, secas em estufa com circulação de ar por um período de 48 horas à $40^{\circ} \mathrm{C}$, trituradas em moinho de facas, peneiradas em peneiras com tamanho de partículas de 100 a 115 mesh e acondicionadas em frascos de polietileno à temperatura ambiente. Para a otimização do tempo foi preparada uma solução individual do metal de interesse de 10 ppm partindo de um padrão analítico de Cd(II) concentração $1000 \mathrm{mg}$. L ${ }^{-1}$.

As vidrarias foram calibradas, limpas e colocadas em solução de ácido nítrico $\left(\mathrm{HNO}_{3}\right)$ a $10 \%$ por um período de 24 horas, enxaguadas com água destilada e secas à temperatura ambiente. Para o ajuste do $\mathrm{pH}$ das soluções foi realizado utilizando soluções de Hidróxido de sódio $\mathrm{NaOH}$ 
e ácido nítrico $\mathrm{HNO}_{3}$ ambas de concentração $0,3 \mathrm{~mol} \mathrm{~L}-1$. O $\mathrm{pH}$ adotado foi de 7.

Foi utilizado o método univariado para a otimização do tempo na faixa de 5 a $40 \mathrm{~min}(5,10,20$ e $40 \mathrm{~min})$.

As soluções contendo $15 \mathrm{~mL}$ do padrão de $\mathrm{Cd}(11)$ e 25 mg do adsorvente foram agitadas no tempo estudado, à temperatura ambiente, em frascos de polietileno e mesa agitadora. Após a agitação as soluções foram filtradas em sistema de filtração simples, utilizando papel de filtro Quanty. Com o sobrenadante foi feita uma análise por Espectroscopia de Absorção Atômica por Chama (FAAS), para a quantificação de íons $\mathrm{Cd}(11)$.

\section{Resultados e Discussão}

Utilizando mesma solução padrão, com massa e pH determinados, foram colocadas sob agitação 3 amostras para cada tempo. Após a agitação e filtração as amostra foram analisadas no FAAS e os resultados estão expressos na tabela e gráfico abaixo.

De acordo com a tabela1 e com o gráfico 1, quanto maior o tempo de agitação maior será a remoção do metal, no entanto foi uma variação pouco significativa, como pode ser observado no gráfico a variação entre 10 e 20 minutos é próxima a variação entre 20 e 40 minutos.

De acordo com os dados obtidos, o tempo de agitação o de 20 min foi considerado o tempo ótimo para as condições estudadas pois apesar de remover menos que o tempo de 40 min sua viabilidade e melhor, uma vez que a diferença de remoção entre os dois é mínima e utilizando um menor tempo tem-se um gasto energético menor e consequentemente menor custo no processo.

Tabela 1. Estudo da variação do tempo na remoção de íons Cd(11) em água.

\begin{tabular}{|c|c|c|c|}
\hline $\begin{array}{c}\text { Tempo de } \\
\text { agitação (min) }\end{array}$ & Absorbância & $\begin{array}{c}\text { Padrão das } \\
\text { amostras }\end{array}$ & \% de remoção \\
\hline 5 & 0,523 & 0,925 & 43,4 \\
\hline 10 & 0,519 & 0,925 & 43,9 \\
\hline 20 & 0,503 & 0,925 & 45,6 \\
\hline 40 & 0,484 & 0,925 & 47,6 \\
\hline
\end{tabular}

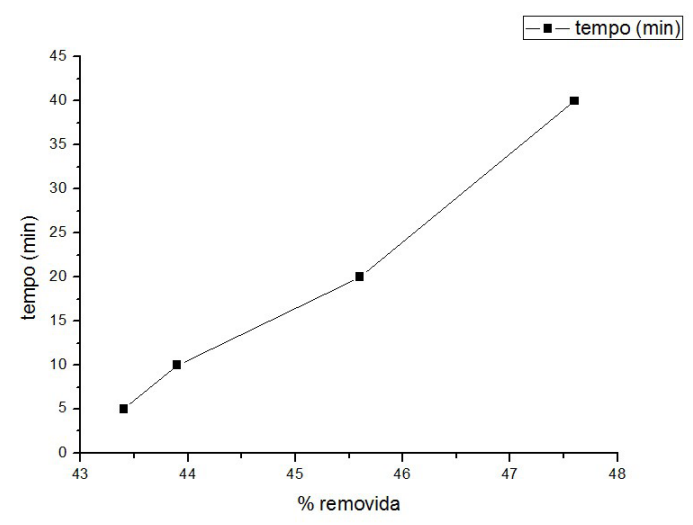

Gráfico 1. Porcentagem de remoção de íons $\mathrm{Cd}(11)$ de acordo com a variação do tempo de agitação.

\section{Conclusões}

A análise da influência do tempo no estudo de adsorção é substancial para o processo, pois o tempo de operação gera gasto energético e maior custo. Logo determinar o tempo mínimo para a reação ocorrer de forma eficiente é primordial para determinar a capacidade máxima adsortiva do material.

\section{Agradecimentos}

Ao Programa Institucional de Bolsas de Iniciação Científica (PIBIC) UEG.

Ao programa de concessão de Bolsa de Incentivo ao Pesquisador (BIP), instituído pela lei estadual n. 18332/2013.

\section{Referências Bibliográficas}

1. Afonso, J. C.; Borges, B. G. A. L.; Silva, C. N.; Guedes, L. K. S. Recuperação de chumbo, mercúrio e elementos dos grupos 4 a 7 da tabela periódica e seus resíduos. Química Nova, vol. 34, p. 720-729, 2011

2. Araújo, C. S. T.; Melo, E. I.; Alves, V. N.; Coelho, N. M. M., Moringa oleiferaLam. Seeds as a Natural Solid Adsorbent for Removal of AgI in Aqueous Solutions. Journal Brazilian Chemical Society, v. 21, p. 1727-1732, 2010 


\section{Artigo Geral 9}

3. ATSDR, Division of Toxicology and Human Health Sciences (proposed), Atlanta, GA; Toxicological Profile For Cadmium, 2012. Disponível em: <www.atsdr.cdc.gov $>$. Acesso em: setembro de 2017.

4. Cardoso, A. P.; Pino, G. A. H.; Veneu, D. M.; Junior Vieira, N. A.; Torem, M. L. O uso de biossorvente natural para remoção de íons $\mathrm{Mn}(\mathrm{II})$ em soluções aquosas. Salvador/Bahia: XXIV Entemme, 2011

5. Lima, V. Ferreira; Merçon, Fábio. Metais Pesados no Ensino de Química. Química nova na escola, v. 33, nº 4, novembro 2011.

6. Neto, J. C. O.; Holanda, C. A.; Santana, S. A. A.; Bezerra, C. W. B.; Silva, H. A. S. Adsorção do corante turquesa remazol por casca de mandioca. Cadernos de Pesquisa, 2013

7. Rodrigues, A. C. D.; Santos, A. M.; Santos, F. S.; Pereira, A. C. C.; Sobrinho, N. M. B. A.Mecanismos de Respostas das Plantas à Poluição por Metais Pesados: Possibilidade de Uso de Macrófitas para Remediação de Ambientes Aquáticos Contaminados. Rev. Virtual Química, janeiro 2017.

\section{Danúbia O. Melo ${ }^{*}$, Lorenna A. Antunes', Túlio N. Matos ${ }^{1}$, Cleide S. T. Araújo' \& Hélen C. Rezende ${ }^{2}$}

${ }^{1}$ Universidade Estadual de Goiás - Campus de Ciências Exatas e Tecnológicas Henrique Santillo

${ }^{2}$ Universidade Federal de Goiás - Regional de Jataí

*E-mail: ddanubia_oliveira@hotmail.com 